\title{
Testing bat abundance and diversity predictions by PREBAT, a connectivity-based habitat suitability model for insectivorous bats
}

\author{
Gesa von Hirschheydt ${ }^{1} \cdot$ Oskar Kindvall ${ }^{2} \cdot$ Johnny de Jong ${ }^{3}$ (D)
}

Received: 13 September 2019 / Revised: 16 January 2020 / Accepted: 14 February 2020 / Published online: 25 February 2020

(C) The Author(s) 2020

\begin{abstract}
Where large landscape modifications are planned, e.g. for infrastructure or exploitation, ecological impact assessments are required because of their potential effects on environment and species. Methods that make such assessments more standardized, efficient, and reliable are highly desirable. This paper proposes a new connectivity-based habitat model for bats (PREBAT), which could be used as a tool for impact assessments. Using data that was specifically collected for this purpose, the performance of PREBAT is critically analyzed and discussed. For this study, 50 sites within an area of $850 \mathrm{~km}^{2}$ in eastern Sweden were inventoried for four nights each using automatic ultrasound recorders to get an empiric measure of bat occurrence that could be compared with PREBAT predictions. The correlation between the predicted values from PREBAT and the observed bat activity (number of recordings) or species richness was tested using generalized linear mixed models. Predicted values of PREBAT are significantly correlated to the number of species that regularly (more than one night) occur at a given site, but not to the total number of species. PREBAT performed also much better at predicting the activity of forest-living species than overall bat activity, which makes PREBAT particularly suitable for predicting conflicts for those species. This study proposes a new habitat model for bats that takes spatial connectivity between habitat patches into account. PREBAT is shown to perform satisfyingly and has the potential to become a useful tool in assessing the ecological impact of large-scale landscape modifications.
\end{abstract}

Keywords Bats (Chiroptera) $\cdot$ Habitat network $\cdot$ Ecological impact assessment $\cdot$ Cost distance analysis $\cdot$ Landscape permeability $\cdot$ Acoustic survey

\section{Introduction}

Human-induced changes in land use are globally ubiquitous and regionally of high importance (Ellis \& Ramankutty 2008, Hansen et al. 2013). With an increase in anthropogenically dominated habitats, previously abundant natural habitats have

Johnny de Jong

johnny.de.jong@slu.se

Gesa von Hirschheydt

gesa.vonhirschheydt@wsl.ch

Oskar Kindvall

oskar.kindvall@calluna.se

1 Swiss Federal Institute for Forest, Snow and Landscape Research WSL, Zürcherstrasse 111, 8903 Birmensdorf, Switzerland

2 Calluna AB, Stora Nygatan 17, 41108 Göteborg, Sweden

3 Swedish Biodiversity Centre, Swedish University of Agricultural Sciences, Box 7016, 75007 Uppsala, Sweden become smaller and more fragmented (Ellis et al. 2010, De Montis et al. 2017).

One important aspect of anthropogenic habitat modifications is the increasing density of longitudinal structures such as roads, often by the opening of remote areas for exploitation (Hunt \& Lester 2009, van der Ree et al. 2015). The effect of roads on wildlife has been studied excessively in mammals, particularly ungulates such as deer species or wild boar which are often involved in collisions with vehicles (Seiler 2004, Gkritza et al. 2010, Niemi et al. 2017). Fahrig and Rytwinski (2009) have reviewed the literature and concluded that, across all animal taxa, roads have negatively affected population densities in the majority of species ( $60 \%$ of 192 cases studied).

Several studies have produced evidence that also bats are affected by roads. Carcass searches, for example, have revealed considerable numbers of traffic casualties in different regions and for different species (Gaisler et al. 2009, Russell et al. 2009, Lesiński et al. 2011). Because insectivorous bats primarily use their hearing as sensory organ when foraging (e.g. Lazure \& Fenton 2011), traffic noise has also been 
associated with decreased foraging efficiency (Schaub et al. 2008, Siemers \& Schaub 2011, Luo et al. 2015) as well as overall avoidance of highways (Zurcher et al. 2010, Bennett \& Zurcher 2013). While avoidance behaviour protects bats from colliding with vehicles, it also prevents them from reaching potential foraging or breeding habitats on the other side of the road. Such barrier effects of roads have, for example, been shown in Bechstein's bat Myotis bechsteinii (Kerth \& Melber 2009). Berthinussen and Altringham (2012) found a higher number of species further away from the road than next to it which suggests that some species perceive the negative effects of roads more strongly or at greater distances. Studies have demonstrated a reduction in bat activity in proximity to major roads (Berthinussen \& Altringham 2012, Kitzes \& Merenlender 2014) with effects extending up to a distance of $1.6 \mathrm{~km}$ where bat activity was three times higher than directly at the road (Berthinussen \& Altringham 2012). Individual species analyses revealed that this pattern was consistent for the four most common species (Kitzes \& Merenlender 2014).

Habitat utilization and ecological requirements of insectivorous bats, independent of the presence of roads, have been studied for decades (de Jong \& Ahlén 1991, Verboom \& Huitema 1997, Kniowski \& Gehrt 2014). One conclusion to draw from these studies is that bats concentrate at sites with high abundance of flying insects, which serve as the main food source (de Jong \& Ahlén 1991, Fukui et al. 2006, Hagen \& Sabo 2012). When observing bats in the wild, however, habitat selection due to foraging opportunities is difficult to separate from habitat selection due to movement or foraging strategies. For example, bats might prefer moving along linear structures because it facilitates orientation, flying along edges that are providing higher insect abundances, or keeping close to higher structures to be less easily perceived by predators. In either case, bats seem to prefer certain structures. Amongst the most utilized habitats are edge zones of open water bodies (Seibold et al. 2013, Kniowski \& Gehrt 2014, Wordley et al. 2015, Nelson \& Gillam 2017). Here, bats do not only find large amounts of insects for feeding, but also drinking water which they require regularly (Seibold et al. 2013). Deciduous and mixed forests, preferably semi-open or in patchy constellations, offer ideal hunting grounds for many bat species and are often used as orientation guides when commuting (Kniowski \& Gehrt 2014, Ducci et al. 2015). Finally, in an otherwise homogeneous landscape, vertical structures such as hedges or tree lines are favoured for both foraging and movement (Verboom \& Huitema 1997, Ashrafi et al. 2013, Kelm et al. 2014, Wordley et al. 2015, Ducci et al. 2015). Crossings of monotonous cropland, on the other hand, are avoided by many species (Kniowski \& Gehrt 2014).

Being able to predict how bats utilize the landscape and how habitat alterations might affect the occurrence of bats is essential for species conservation. As all bat species occurring in Europe are listed in appendix IV of the Habitats Directive of the European Union (Council Directive 92/43/EEC), they are legally protected from hunting, handling, or any type of disturbance in all countries belonging to the European Union. This also implies an obligation to maintain environmental conditions that ensure the long-term persistence of this organism group.

In order to create a tool that would facilitate the prediction of bat occurrences as well as potential areas of conflict, we have developed a mechanistic, spatial model that is based on landscape characteristics and on habitat requirements and behaviour patterns of insectivorous bats. This model, PREBAT, integrates the knowledge accumulated in the scientific literature as well as additional expert knowledge to predict the location of summer roosts, the points where bats concentrate at different times of the year, and which routes they are most likely to use when moving through the landscape.

The purpose of this study is to evaluate the performance and utility of a selection of the variables predicted by our model PREBAT. We gathered data about activity and species richness of bats to (1) see whether field data was significantly correlated with the predicted values of the different variables, (2) investigate whether any additional variable (e.g. proximity to large roads) might explain the residuals, and (3) discuss the limitations, assumptions, and the potential of PREBAT in order to make suggestions for the future development and utilization of this tool for stakeholders.

\section{Methods}

\section{Model description}

A habitat network model for bats, named PREBAT, was developed (PREdicting BAT abundance). The model uses a set of publicly available geographical data (Table 1) to make spatially explicit predictions about bat landscape utilization. The model takes several important aspects of bat population ecology into account, that is, temporal variation in habitat quality, spring migration, and female foraging behaviour around breeding colonies. The PREBAT model predicts where in the landscape bats are most likely to forage during spring when insects are restricted to certain combinations of habitats, where summer colonies are most likely to be established, where bats are expected to cross infrastructure, or which routes bats are most likely to take when moving from one place to another. In this study, we tested only those predictors that reflect abundance of bats during summer when females are expected to stay close to their roosting sites.

The construction of the model consisted of a number of stepwise calculation procedures, which were implemented using a set of ArcGIS methods linked together in a workflow 
Table 1 The data layers that were used as input data to create PREBAT. For each data layer used, it is specified which features were selected

\begin{tabular}{|c|c|c|c|}
\hline Output map layer & Selection & Input map layers & Source \\
\hline Habitat & All CadasterENV habitat classes & $\begin{array}{l}\text { CadasterENV_AB } \backslash \mathrm{AB} \backslash \text { Classes } \backslash \\
\text { lc_hr_ab_ogen_3_2.tif }\end{array}$ & CadasterENV, Metria \\
\hline Tree cover & & ab_tree_cover.tif ${ }^{--}$ & CadasterENV, Metria \\
\hline Pastures & Land use = "pasture" & AB_LandUse.shp, C_LandUse.shp & CadasterENV, Metria \\
\hline Hard wood trees & All hardwood trees & $\begin{array}{l}\text { Several point layers with trees found } \\
\text { in different monitoring programs } \\
\text { of valuable trees }\end{array}$ & $\begin{array}{l}\text { The tree portal, Swedish University } \\
\text { of Agricultural Sciences, data from } \\
\text { County Administrations of } \\
\text { Stockholm and Uppsala }\end{array}$ \\
\hline $\begin{array}{l}\text { Hollow trees } \\
\text { being potential } \\
\text { colony sites }\end{array}$ & $\begin{array}{l}\text { Hard wood trees with indications } \\
\text { of present hollows }\end{array}$ & $\begin{array}{l}\text { Several point layers with trees found in } \\
\text { different monitoring programs of } \\
\text { valuable trees }\end{array}$ & $\begin{array}{l}\text { The tree portal, Swedish University } \\
\text { of Agricultural Sciences, data from } \\
\text { County Administrations of Stockholm } \\
\text { and Uppsala }\end{array}$ \\
\hline $\begin{array}{l}\text { Buildings being } \\
\text { potential colony } \\
\text { sites }\end{array}$ & $\begin{array}{l}\text { KKOD in }(731,732,733,734,735 \\
\quad 736,737,741,747,748,753)\end{array}$ & BS_01.shp, BS_03.shp & GSD terrain map (vector), Lantmäteriet \\
\hline Shorelines & $\begin{array}{l}\text { KKOD in }(102,104,105,107,108,110, \\
\quad \begin{array}{l}112,113,114,115,116,117,119,120,218, \\
418,518,718,1418,1518,1618,1718, \\
1819,1820)\end{array}\end{array}$ & ML_01.shp, ML_03.shp & GSD terrain map (vector), Lantmäteriet \\
\hline Streams & KKOD in $(441,455,456)$ & HL_01.shp, HL_03.shp & GSD terrain map (vector), Lantmäteriet \\
\hline Highways & $\mathrm{KKOD}=5011$ & VL 01.shp, VL 03.shp & GSD terrain map (vector), Lantmäteriet \\
\hline
\end{tabular}

(Fig. 1). The result of each step was a map layer that became the input in the subsequent procedure (Fig. 2).

\section{Habitat map}

In the first step, we constructed a habitat raster map covering the study area in south-eastern Sweden (see "Site description and fieldwork") with a buffer zone of $20 \mathrm{~km}$ in order to avoid edge effects in the subsequent model calculations. In this step, the basic habitat classes in the National Land Cover Map of Sweden (Metria AB, 2015) were complemented with information from vector layers listed in Table 1, i.e. the point layers on hardwood trees and the line layers with streams from different sources. Narrow streams and single old hardwood trees are landscape elements that are expected to be associated with high concentrations of insects but are underrepresented in the land cover map due to its resolution of $10 \times 10 \mathrm{~m}$.

\section{Insect abundance map (IA)}

In the second step, we created a raster map representing the habitat quality in terms of expected availability of insects that the modelled bats are supposed to feed on. For each raster pixel, a biotope-specific index of insect abundance (IA) was calculated based on the parameters listed in Table 2. The parameters were set based on long-term experience from different Swedish studies on bat foraging behaviour in relation to measured insect abundance (de Jong et al. unpubl.).

The initial values of IA were based on the biotope map according to the parameters in Table 2. Depending on whether or not the biotope is grazed according to the map of land use, the IA index was increased, because presence of grazing animals increases the abundance of flying insects (Evans et al. 2007), especially Diptera and Carabidae, which feed on the dung. Proximity to water is also expected to increase the density of flying insects in the environment (Jackson \& Resh 1989) as many insect species develop as larvae in streams or lakes. To reflect this pattern, basic quality values of some habitat types were adjusted within a distance of $250 \mathrm{~m}$ from the line features in the map layers with shorelines and streams according to Table 2 .

\section{Flight friction map (FF)}

In the third step, we created a map describing the flight permeability of the landscape for bats. In this map, a flight friction (FF) value was calculated for each pixel based on the habitat map and the friction parameters listed in Table 2. As with IA, the initial habitat-specific friction values were adjusted depending on the proximity to different landscape elements affecting bat foraging behaviour.

Many of the small bat species prefer to fly in forest gaps and along forest edges instead of flying through dense forest or in open habitats (de Jong 1994). To incorporate this behaviour into the habitat network model, the information from a tree cover raster layer (Table 1) was used. In this layer, grid cell values with $\leq 70 \%$ tree cover occur along forest edges or where gaps of various sizes make the forest less dense. Hence, this threshold was used to adjust friction values from what was expected from the habitat type per se when close to forest edge (Table 2). 


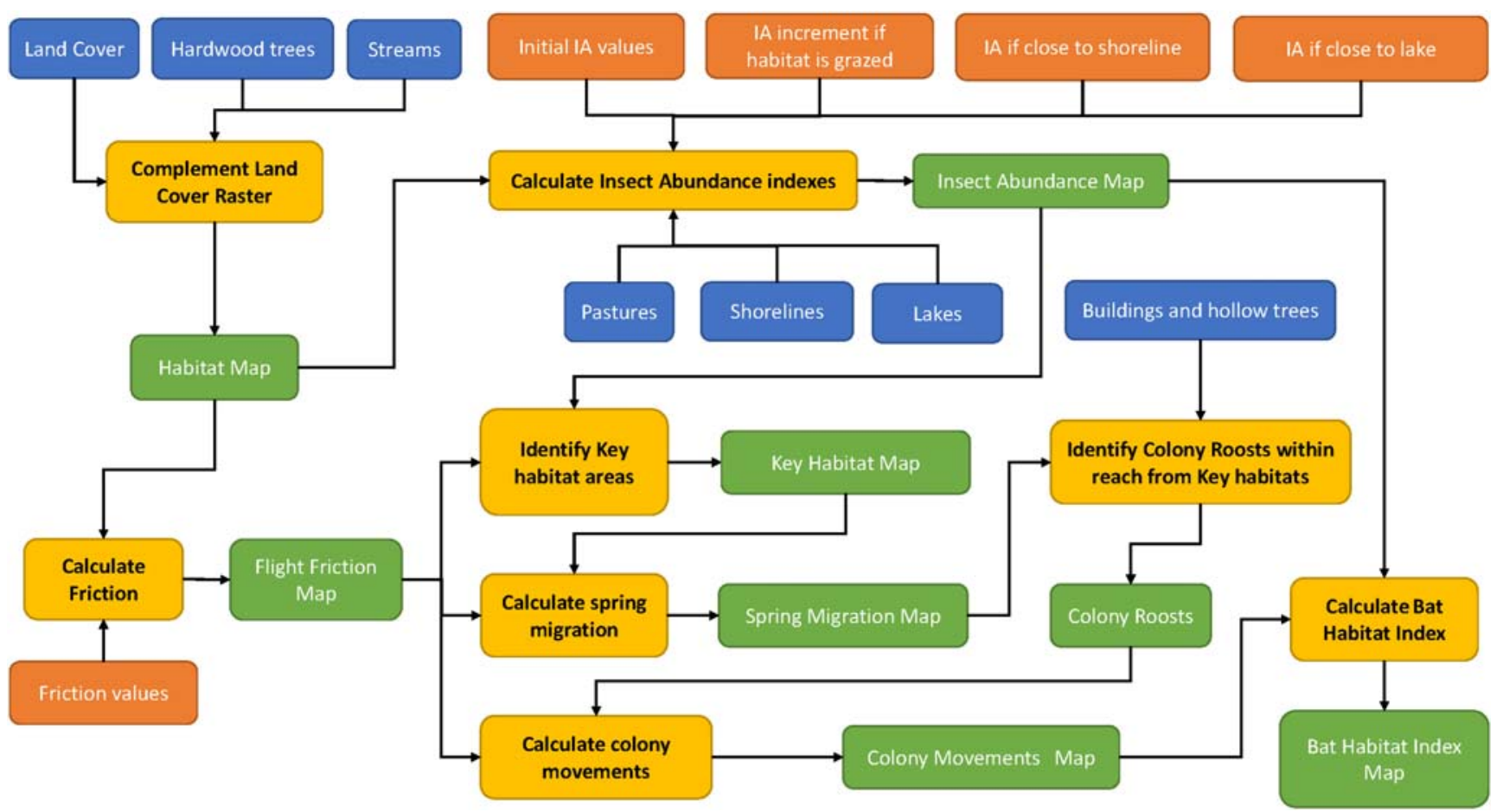

Fig. 1 Flow chart of the different steps used in the creation of PREBAT

Some bat species fly over water surfaces and seem to follow streams when crossing through open arable landscape sections (de Jong et al. unpubl.). However, at least some of the species may avoid flying over larger water areas (Ciechanowski 2002). These patterns were incorporated into the model by setting relatively high basic friction values for water habitats unless the distance to the shoreline is within $250 \mathrm{~m}$ (Table 2).

\section{Key habitat map}

During spring and autumn, bats primarily forage in deciduous forests in the vicinity of rather nutritious lakes where insect abundance is still high even when insect productions have almost ceased in all other types of habitats (de Jong \& Ahlén 1991). Deciduous forests situated close to lakes are often referred to as key environments as their availability is a crucial factor affecting the long-term abundance of bats in the whole landscape (de Jong 1994). In the generated insect abundance map, pixels with values equal to 5 correspond to bat key habitats. However, some fragments of deciduous forest, that are close enough to lakes to fulfil the criteria of being key habitat, are too small to support even a very few individuals of bats during periods of poor climatic conditions. In order to delimit all key habitat patches large enough to be utilized by a local bat population, the Cost Distance method in ArcGIS was applied utilizing the friction raster. Dispersal was originated from each fragment with an IA value equal to 5. The maximum distance was set to $100 \mathrm{~m}$. The resulting
Cost Distance raster was converted to a polygon layer. From this layer, all separate polygons greater or equal to 1.0 ha were selected as functional key habitat patches.

\section{Spring migration map}

During summer, the production of insects that can be used as a food resource by bats becomes much more evenly distributed in the landscape (de Jong 1994). It is thereby possible for bats to migrate to other areas than the key habitats in order to find good places to establish their maternity colonies. The Cost Distance method in ArcGIS was applied on the friction raster to resemble the spring migration from all identified key habitat patches. The calculations were in this case limited to a maximum distance of $10 \mathrm{~km}$.

\section{Map of potential colony roosts}

The Cost Distance raster representing the spring migration was converted to a polygon layer representing the area assumed to be reachable by bats. Using this polygon layer, it was possible to select all patches with high quality value $(\geq 4)$ within reach for migrating bats. In order to ensure that at least one high-quality habitat patch should be within reach for a colony, the Cost Distance algorithm was applied on the friction raster starting from the identified high-quality patches and setting the maximum dispersal distance to $1500 \mathrm{~m}$. Converting the resulting Cost Distance raster to a polygon layer made it possible to select all buildings and hollow trees 
Fig. 2 Illustration of different stages of the PREBAT modelling.

The maps display different variables from the same location. The first row shows an orthophoto (left) and a simplified terrain map (right), followed by the primary maps for insect abundance (IA) and flight friction (FF) in the middle row. Colony movement $(\mathrm{CM})$ on the bottom left represents the penultimate stage in the construction of the BHI; the black dots in this map indicate potential colony sites. The final bat habitat index (BHI) is shown on the bottom right. In all maps, the red colour represents favourable conditions for bats, whereas the blue colour represents unfavourable conditions
Coordinate system: SWEREF99 TM Data source: Lantmäteriet (Ortofoto raster, Terrängkartan vektor)
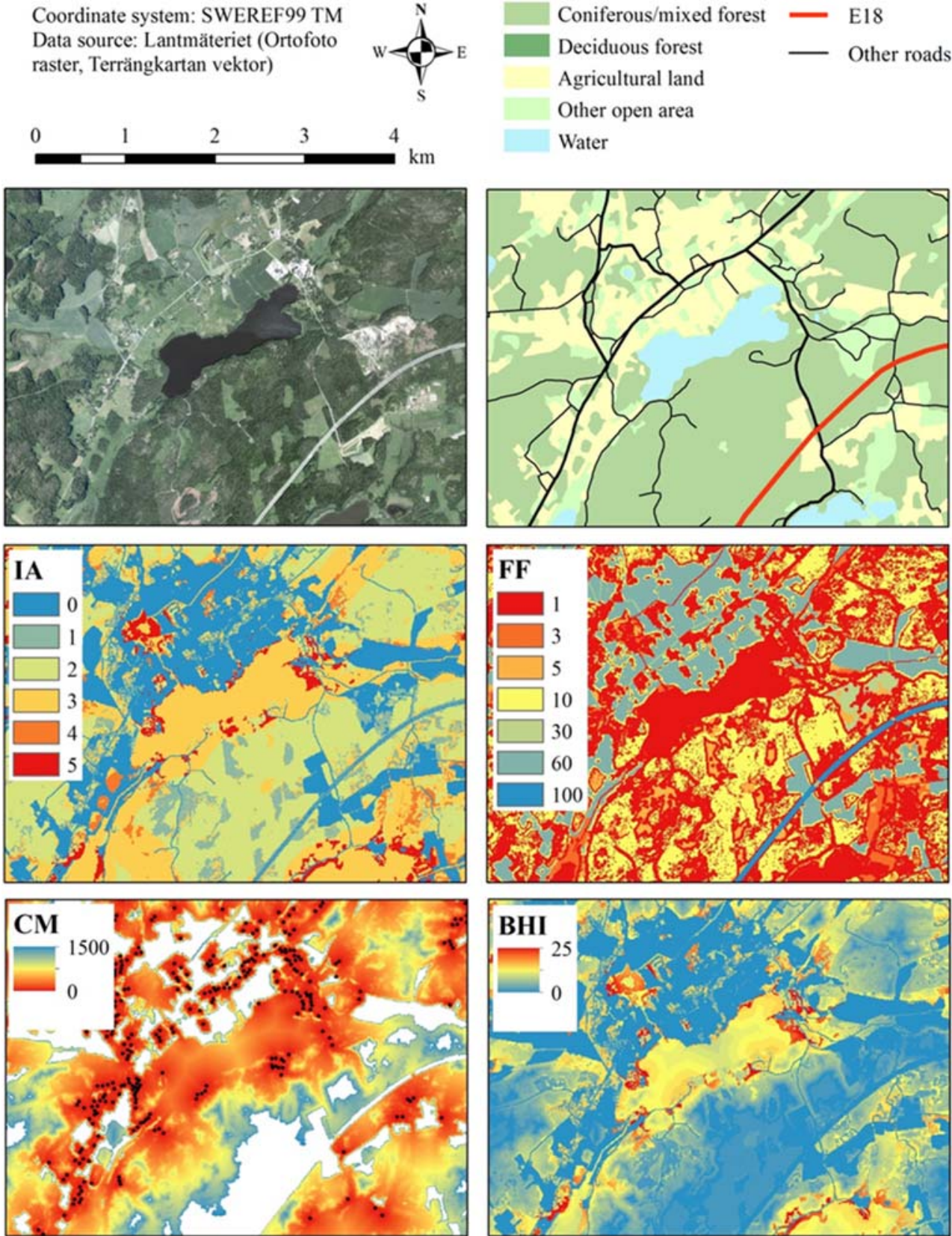

Coniferous/mixed forest - E18

Deciduous forest

Agricultural land

Other open area

Water

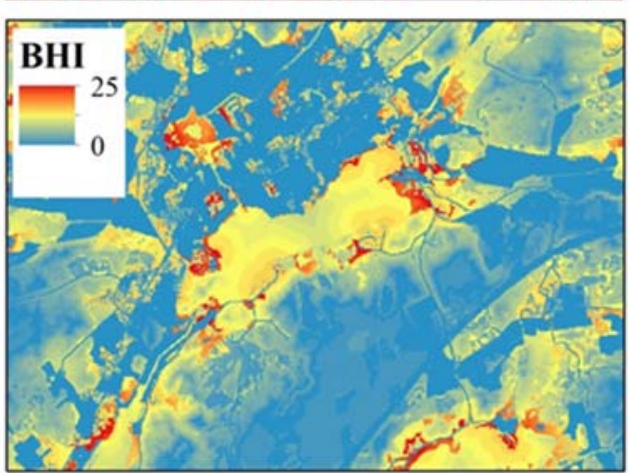

from corresponding data layers listed in Table 1 that are practically reachable by bats during spring migration and close enough to good foraging sites to be potentially utilized as colony roosts.

\section{Colony movement map (CM)}

To model the foraging of reproductive females during the summer season, the Cost Distance algorithm was applied on the friction raster starting from all potential colony sites that were identified as reachable by bats. The maximum distance was set to $1500 \mathrm{~m}$. These calculations generated predictions of the home range of each potential colony and the bat habitat network during summer.

\section{Bat habitat index map (BHI)}

In order to predict where bats are most likely to be observed during summer foraging, an index (bat habitat index [BHI]) was constructed. This index combines the information from the cost distance analysis of the summer foraging, i.e. the colony movement $(\mathrm{CM})$, with the information from the insect abundance (IA) map: 
Table 2 Habitats and habitatspecific model parameters that were used to create PREBAT

\begin{tabular}{|c|c|c|c|c|c|c|c|}
\hline \multirow[b]{2}{*}{ Habitat type } & \multicolumn{4}{|c|}{ Quality } & \multicolumn{3}{|c|}{ Friction } \\
\hline & Basic & $\begin{array}{l}\text { Added if } \\
\text { within } \\
\text { pasture }\end{array}$ & $\begin{array}{l}\text { If } \\
<250 \mathrm{~m} \\
\text { from } \\
\text { water }\end{array}$ & $\begin{array}{l}\text { If } \\
<250 \mathrm{~m} \\
\text { from } \\
\text { lake }\end{array}$ & Basic & $\begin{array}{l}\text { If } \\
<250 \mathrm{~m} \\
\text { from } \\
\text { shoreline }\end{array}$ & $\begin{array}{l}\text { If }<250 \mathrm{~m} \\
\text { from } \\
\text { forest edge }\end{array}$ \\
\hline $\begin{array}{l}\text { Pine forest (not on } \\
\text { wetland) }\end{array}$ & 2 & 1 & 3 & 3 & 10 & 10 & 1 \\
\hline $\begin{array}{l}\text { Spruce forest (not on } \\
\text { wetland) }\end{array}$ & 2 & 1 & 3 & 3 & 10 & 10 & 1 \\
\hline $\begin{array}{l}\text { Mixed coniferous forest } \\
\text { (not on wetland) }\end{array}$ & 2 & 1 & 3 & 3 & 10 & 10 & 1 \\
\hline $\begin{array}{l}\text { Mixed forest (not on } \\
\text { wetland) }\end{array}$ & 2 & 1 & 3 & 3 & 10 & 10 & 1 \\
\hline $\begin{array}{l}\text { Deciduous forest (not on } \\
\text { wetland) }\end{array}$ & 3 & 1 & 4 & 5 & 5 & 5 & 1 \\
\hline $\begin{array}{l}\text { Deciduous hardwood } \\
\text { forest (not on wetland) }\end{array}$ & 3 & 1 & 4 & 5 & 5 & 5 & 1 \\
\hline $\begin{array}{l}\text { Deciduous forest with } \\
\text { deciduous hardwood } \\
\text { forest (not on wetland) }\end{array}$ & 3 & 1 & 4 & 5 & 5 & 5 & 1 \\
\hline $\begin{array}{l}\text { Temporarily non-forest } \\
\text { (not on wetland) }\end{array}$ & 1 & 1 & 2 & 2 & 5 & 5 & 1 \\
\hline Pine forest (on wetland) & 2 & 1 & 3 & 3 & 10 & 10 & 1 \\
\hline Spruce forest (on wetland) & 2 & 1 & 3 & 3 & 10 & 10 & 1 \\
\hline $\begin{array}{l}\text { Mixed coniferous forest } \\
\text { (on wetland) }\end{array}$ & 2 & 1 & 3 & 3 & 10 & 10 & 1 \\
\hline Mixed forest (on wetland) & 2 & 1 & 3 & 3 & 10 & 10 & 1 \\
\hline $\begin{array}{l}\text { Deciduous forest (on } \\
\text { wetland) }\end{array}$ & 3 & 1 & 4 & 5 & 5 & 5 & 1 \\
\hline $\begin{array}{l}\text { Deciduous hardwood } \\
\text { forest (on wetland) }\end{array}$ & 3 & 1 & 4 & 5 & 5 & 5 & 1 \\
\hline $\begin{array}{l}\text { Deciduous forest with } \\
\text { deciduous hardwood } \\
\text { forest (on wetland) }\end{array}$ & 3 & 1 & 4 & 5 & 5 & 5 & 1 \\
\hline $\begin{array}{l}\text { Temporarily non-forest } \\
\text { (on wetland) }\end{array}$ & 1 & 1 & 2 & 2 & 5 & 5 & 1 \\
\hline Open wetland & 3 & 1 & 3 & 3 & 3 & 3 & 1 \\
\hline Arable land & 0 & 1 & 0 & 0 & 60 & 60 & 10 \\
\hline $\begin{array}{l}\text { Non-vegetated other open } \\
\text { land }\end{array}$ & 1 & 1 & 1 & 1 & 30 & 30 & 1 \\
\hline Vegetated other open land & 1 & 1 & 2 & 2 & 5 & 5 & 1 \\
\hline Built-up areas & 0 & 0 & 0 & 0 & 30 & 30 & 1 \\
\hline Non-built-up areas & 0 & 0 & 0 & 0 & 30 & 30 & 1 \\
\hline Inland water surfaces & 3 & 0 & 3 & 3 & 60 & 1 & 1 \\
\hline Marine water surfaces & 1 & 0 & 1 & 1 & 60 & 3 & 1 \\
\hline Highways & 0 & 0 & 0 & 0 & 100 & 100 & 100 \\
\hline
\end{tabular}

$$
\mathrm{BHI}=s \times \mathrm{IA} \times\left(\mathrm{CM}_{\max }-\mathrm{CM}\right)
$$

where $s$ is a scaling factor which, in the current setup, was set equal to $1 / 300$. This factor allows the index to vary within a range of 0 to 25 . The BHI indicates the quality of the habitat in terms of both expected food availability and the reachability from available roosting sites.

\section{Site description and fieldwork}

The study area was located around and southwest of Norrtälje in the province of Uppland, Sweden (Fig. 3), extending to Rimbo in the west and to Brottby in the south. This area was chosen because all input data were available for the entire area and because the area encompasses a large portion of the 
highway E18, which made it possible to assess the effect of a large road on bat occurrence.

Sampling sites were chosen according to a stratified random method that covered $\mathrm{BHI}$ values across the entire gradient of possible values (0-25) and that positioned the same amount of sites near and far from the highway. In a first step, 1000 points were randomly distributed in the study area with a min. distance of $60 \mathrm{~m}$ to each other, using ArcMap 10.4.1 (ESRI 2016). For each of these points, the mean BHI value of all cells lying within a $30 \mathrm{~m}$ radius around this point $\left(\mathrm{BHI}_{30}\right)$ was extracted (using the function spatial statistics as table in ArcMap) and all points were sorted into one of three categories depending on their $\mathrm{BHI}_{30}$ values: high (values 17-25), intermediate (8-14), and low (3-6). In addition to the importance of the local BHI, we expected that the interaction between the local habitat (30 m radius) and the surrounding habitat would be important for the number of bats, because it is more likely that a small patch of good habitat would be used if it lies within a larger good patch. Therefore, the mean BHI of all cells lying within a ring of $170 \mathrm{~m}$ breadth around the $30 \mathrm{~m}$ radius was extracted to be used as a second variable in the analysis. Based on the mean BHI of the surrounding habitat $\left(\mathrm{BHI}_{170}\right)$, all 1000 points were further sorted into groups: high (17-25), intermediate (8-14), and low (3-6). To see whether proximity to the road had an effect on the performance of the BHI or the occurrence of bats, the points were further split into two groups, depending on whether they were close to $(<2000 \mathrm{~m})$ or far away from $(>2000 \mathrm{~m})$ the highway E18. In these three steps, the 1000 points were split into $3 \times$ $3 \times 2(=18)$ groups. From each of these groups, the two to three random points were picked as sampling locations. Points in the middle of water or open areas were excluded. Due to practicalities in the field, some locations had to be slightly adjusted. Practicalities included finding a suitable tree for attaching the recording devices, avoiding crossing fences or private ground, or agreement of a house- or landowner on where to install a recorder. The distribution of the sampling sites is shown in Fig. 3. Every site was inventoried four nights, with the fourth repetition being at least 9 days after the first repetition and with an interval of min. two days between two repetitions of the same location (five exceptions where inventories were performed on two consecutive days). All data were gathered during 23 nights between the 3rd and the 27th of July 2017. During this time, average night temperatures were always above $8{ }^{\circ} \mathrm{C}$, total precipitation was less than $3 \mathrm{~mm}$, and wind speed never exceeded $3 \mathrm{~m}$ per second (calculated per night from hourly observations between $9 \mathrm{pm}$ and $6 \mathrm{am}$; data from the weather station Norrtälje; SMHI 2018). Therefore, the climatic conditions were judged as suitable for bats and no observations were excluded due to weather. Weather was not included as a covariate in the analysis.
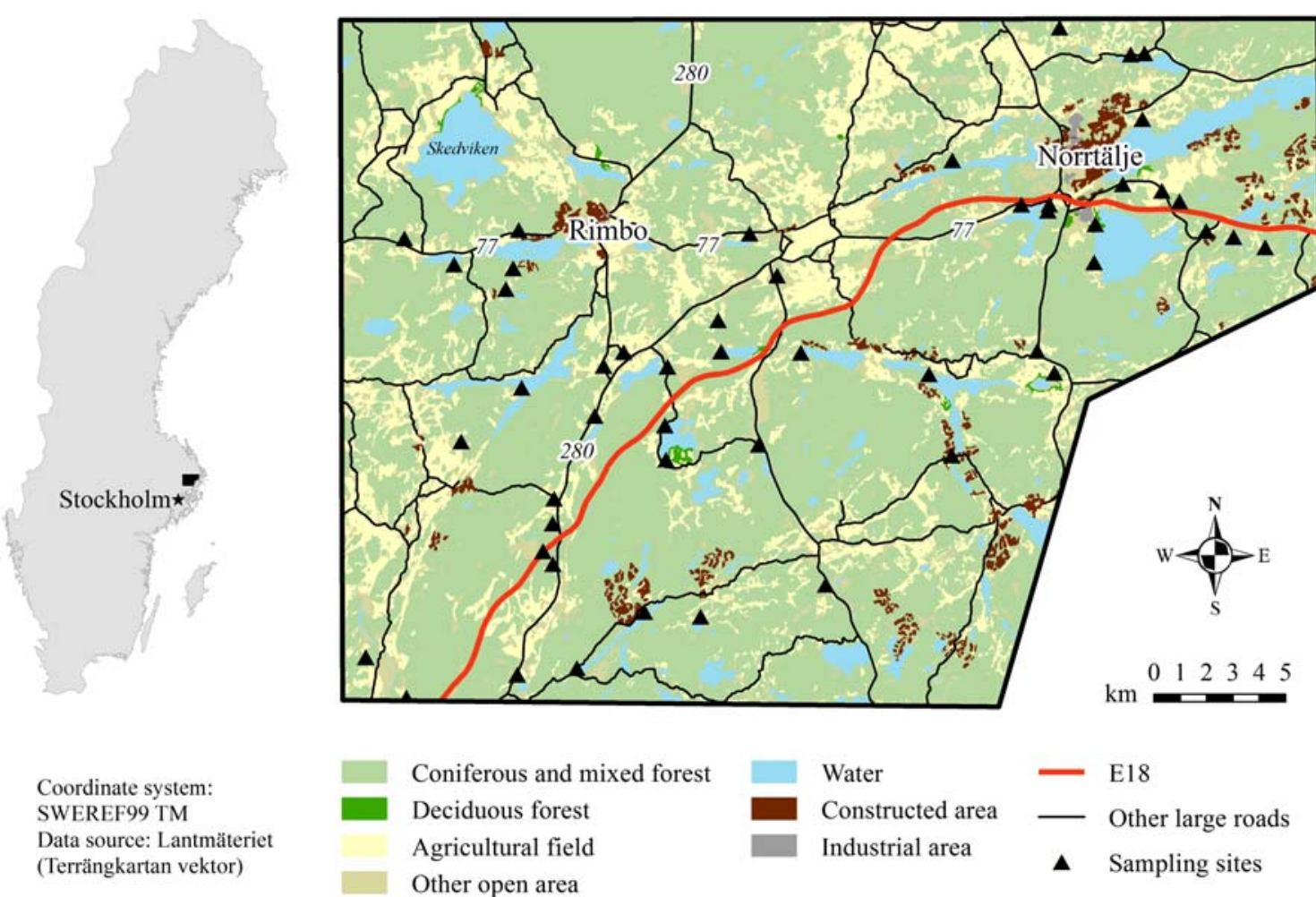

Fig. 3 The study area, here surrounded by a black line, has an area of approximately $850 \mathrm{~km}^{2}$ and belongs to the province of Uppland. The highway E18 (red line) crosses the study area from southwest to

northeast. The 50 sampling sites (black triangles) were distributed according to a stratified random sampling method. The location of the study area within Sweden is shown in the inset map to the left 
Twenty D500X ultrasound recorders (Pettersson Elektronik AB, n.d.) were used to record bat calls. The automatic recording device is here referred to as auto-boxes. They were placed onto branches of trees at 3 to $6 \mathrm{~m}$ height with the microphone facing the direction least covered with leaves, needles, or branches. The recorders were set to operate passively at a low-power mode from $9.30 \mathrm{pm}$ to 4.30 am during the first period of the study and after the 16th of July from $9 \mathrm{pm}$ to $5 \mathrm{am}$, in order to adjust to a later sunrise and earlier sunset. The device started recording only when a sound above $15 \mathrm{kHz}$ was detected. Recordings were stored as WAV files on a memory card placed inside the auto-box. A minimum interval of $5 \mathrm{~s}$ between two consecutive recordings was defined in order to avoid emptying the batteries too quickly. Due to an error in the field, unfortunately not all auto-boxes had the same setting for recording length. Most auto-boxes recorded for a 5-s time span, but a few auto-boxes (and more in the beginning of the study) recorded for only $3 \mathrm{~s}$ each time. Length of recording was therefore added as a covariate in the statistical models to control for its major effects on the number of recordings.

\section{Sound analysis}

In a first step, all sound files were analyzed using the software Omnibat version 1.16 (Ecocom AB, 2017). This software visually compares the sonogram of each recording with those of an internal library with confirmed recordings and assigns each recording to the category with the highest match. In a second step, every file was looked at manually to either confirm or correct the category suggested by the program, and to add species tags where more than one species was recorded. Where species identification required more detailed analysis, the call intensity, length, and frequency were studied in the software BatSound (Pettersson Elektronik AB, n.d.). Later during the process of data handling, the identity of the original recording was omitted and only the number of recordings per species kept, which means that a single recording including three different species counted as three bat recordings. Bat calls were identified to species level where possible. For some recordings, however, higher taxonomic levels (Myotis sp., Eptesicus sp., Nyctalus sp., and Microchiroptera) had to be used.

\section{Statistical evaluation of the model performance}

The performance of different indices of PREBAT was statistically tested using two datasets, both derived from the same field study. The first dataset contained information about the number of species per site (number of observations, $n=50$ ). Three measures of species richness were evaluated: (1) total number of species, (2) number of regular species (number of species recorded during at least three out of four nights, and
(3) number of very regular species (number of species recorded in each of the four nights). For this dataset, the performance of the indices was assessed using generalized linear models and a Poisson distribution for the response variable (i.e. different measures of species richness).

The second dataset was used to assess bat activity at the auto-box level (number of observations, $n=200$ ). Activity was analyzed as (1) the total number of bat recordings, (2) the number of bat recordings belonging to the guild of forest species, (3) the number of bat recordings belonging to the guild of aerial-hawking species, and (4) the number of bat recordings belonging to the guild of water-surface species. For these guild-specific analyses, the species were divided based on their ecological foraging habitat, i.e. forests with forests edges and narrow spaces (all species of the genera Pipistrellus and Plecotus as well as the species Myotis brandtii/mystacinus and M. nattereri), open spaces (aerialhawking species; all species of the genera Nyctalus, Eptesicus, and Vespertilio), and open water (water-surface species; Myotis daubentonii and M. dasycneme). Ambiguous identifications such as Myotis sp. and Microchiroptera were ignored. In addition to these measures of activity, the number of species recorded during any given night was also assessed. Analyses of this dataset were performed using generalized linear mixed models (GLMM; glmer function from the lme4 package; Bates et al. 2015) with number of recordings/species as a Poisson-distributed response variable. Sampling site and auto-boxes were treated as random effects factors, with autoboxes nested within sampling sites. Day since the beginning of the study was added as covariate in all models, and length of recordings was included as covariate in the models for total activity, activity of forest species, and activity of aerialhawking species, because it had a significant effect on the response in those. The models for total activity and activity of aerial-hawking species also included a significant interaction between date and recording length, because there had been more boxes with shorter recording lengths in the beginning than in the end of the study.

For both datasets, the predictor variables of interest were extracted from maps in different stages of development in the construction of the BHI. Values were taken from the primary maps for insect abundance (IA) and flight friction (FF), from the penultimate step of the construction of the BHI, called colony movement (CM), and from the final index (BHI). For each sampling site, mean values of the BHI, IA, FF, and CM were calculated for areas of 30, 200, and $500 \mathrm{~m}$ radius around the position of the auto-box (notation $\mathrm{BHI}_{30}, \mathrm{IA}_{200}$, etc.) to explore the influence of scale. The BHI value was also averaged over a circular ring of $170 \mathrm{~m}$ breadth surrounding the $30 \mathrm{~m}$ radius. Additionally, the shortest distance between each site and the highway E18 was calculated. This factor was tested in addition to and in interaction with the BHI. All statistical analyses were performed in R (R Core Team 2017). 
For each statistical model, the Akaike information criterion (AIC; Akaike 1998) was extracted and the bias-corrected AICc for small sample size was calculated (according to recommendation by Burnham \& Anderson 2002). Within each set of models (i.e. all models sharing the same response variable), the difference $(\Delta)$ in AICc between each model and the model with the lowest AICc was calculated. The best models (lowest AICc or $\triangle \mathrm{AICc}=0$ ) were selected, and statistical significance and effect sizes were extracted for all parameters. Correlation between response variables was assessed with a Pearson correlation test.

\section{Results}

\section{Species occurrences}

In a total of 48,205 recordings, 16,030 bats could be identified. The other recordings contained calls of other animals (primarily bush crickets), rain, traffic, or other humaninduced noise. In total, twelve different bat species were recorded. The species observed at most sites were the northern bat Eptesicus nilssonii, the common noctule Nyctalus noctula, and the soprano pipistrelle Pipistrellus pygmaeus (48, 46, and 44, respectively, of a total of 50 sites; Fig. 4). The northern bat and the common noctule were also the most active species, together representing $71 \%$ of all recordings $(n=16,030$; Fig. 5). Because both species belong to the guild of aerialhawking bats, this species group was also by far the most active (74\% of all recordings; Fig. 6 ). On the other extreme of the spectrum, the Nathusius' pipistrelle Pipistrellus nathusii was only recorded 18 times and the pond bat Myotis dasycneme only three times. It is worth mentioning that the common pipistrelle Pipistrellus pipistrellus was recorded 170 times at three different sites, of which one site was frequented every night. To our knowledge, these observations represent the most northern finds of this species in Sweden.

\section{Statistical evaluation of the performance of PREBAT}

For all measures of species richness, the model with $\mathrm{CM}_{30}$ as the single independent variable consistently performed best (Table 3). The correlation was not significant for the total number of species ( $p$ value $=0.198$ ), but highly significant for the number of regular species, the number of species per night, and the number of very regular species ( $p$ values of $0.005,0.001$, and $<0.001$, respectively; Table 4).

For total activity, the best-performing model included the explanatory variables $\mathrm{BHI}_{200}(p$ value $=0.055)$, distance to the highway $(p$ value $=0.025)$, and their interaction $(p$ value $=$ $0.069)$. The same variables were included in the best model for the activity of forest species; $\mathrm{BHI}_{200}(p$ value $=0.002)$, distance to the highway ( $p$ value $=0.367$ ), and their interaction
( $p$ value $=0.019)$. The best-performing model for the activity of aerial-hawking species included only $\mathrm{CM}_{30}$ ( $p$ value $=$ $0.013) . \mathrm{FF}_{30}$ was the only significant predictor of activity of water-surface bats, but all models with this response variable were strongly zero-inflated (129 data points of 200 had the value 0 ) and this result is therefore not discussed.

Number of species recorded per night was significantly correlated with the total activity (Pearson's $r=0.44, p$ value $<0.001$ ), and the total number of species per site was significantly related to the number of very regular species $(r=0.54$, $p$ value $<0.001)$ and regular species $(r=0.6, p$ value $<0.001)$.

\section{Discussion}

The purpose of this study was to evaluate the performance of a connectivity-based habitat model for predicting bat occurrence (PREBAT), by correlating bat occurrence data with predicted index values. The results suggest that the index performs well, particularly when predicting the number of regularly occurring species as well as the activity of forest-living species.

For all measures of species richness, models with the BHI as explanatory variable performed worse than models with the colony movement $(\mathrm{CM})$ variable. This result suggests that the last step in the creation of the BHI can be omitted. The last step is the overlay of a cost distance analysis (colony movement) that started from the selected colony sites with insect abundance. As colony sites were selected according to a minimum level of insect abundance, there might be enough insects anyway so that bats can follow their habitat preferences instead of having to balance feeding efficiency with flying preferences.

The BHI performed much better at predicting the number of very regular species than the total number of species. This suggests that the factors included in the BHI (insect abundance and flight friction) are primarily of importance for bats to determine where they utilize a site repeatedly. We suspect that some of the species that were recorded only once or twice at a site consisted of individuals passing the site on their way to another area. In that case, the occurrence is rather due to other factors (population dynamics, behaviour, etc.) than to the variables used in the BHI.

The BHI variable in the model for overall bat activity did not have a significant effect on the overall bat activity. However, when predicting the activity of only forest-hunting species, the BHI had a highly significant effect. This result suggests that the relative weighting of habitat types underlying the BHI better represents habitat preferences of forest bats compared with those of other hunting guilds. As forest species are amongst the more vulnerable bats in Sweden, in terms of both conservation status and affectedness by habitat 
Fig. 4 Proportion of sites (a) and auto-boxes (b) where species were recorded. The proportion of sites $(n=50)$ and auto-boxes $(n=$ 200) represents the number at/in which a species was observed at least once. The two aerialhawking species northern bat (Eptesicus nilssonii) and common noctule (Nyctalus noctula) and the forest-living species soprano pipistrelle (Pipistrellus

pygmaeus) were the most common species, both in the geographical extent and in the overall occurrence based on recordings a
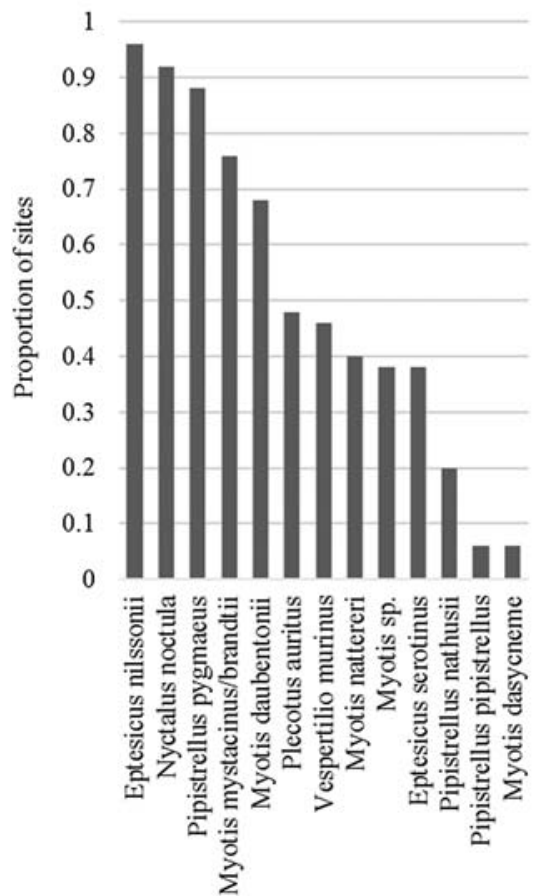

b

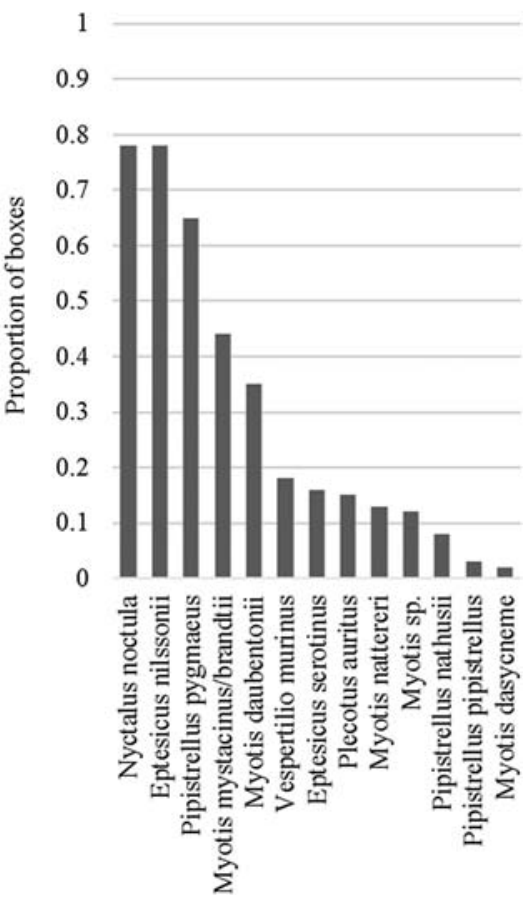

modifications (Artdatabanken 2015, Trafikverket 2015), this bias of the BHI is desirable for its future use.

For the interpretation of the BHI's predictions, it is essential to know at which scale its underlying factors operate. The only way to evaluate this is to compare the BHI's performances at different scales. The results suggest that the scale at which the BHI works best depends on what it is supposed to predict. All measures of species richness were best predicted at a scale of $30 \mathrm{~m}$ radius. The same was true when predicting the activity of aerial-hawking species. For both the total activity and the activity of forest species, however, the BHI performed best at a scale of $200 \mathrm{~m}$ radius.

The distance to the highway E18 was tested as an additional predictor variable in the statistical models to see whether the

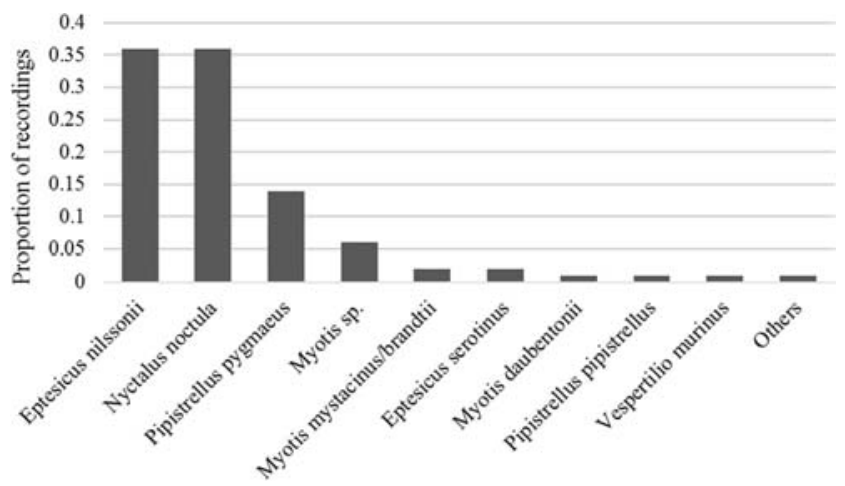

Fig. 5 Recording frequencies of different species. The bars represent the proportion of recordings for each species (or taxonomic unit) compared with the total number of recordings $(n=16,030)$. All species with less than $0.01 \%$ of all recordings are summed together presence of a large road had any effect on bat occurrence that the BHI had not accounted for. The effect of distance on overall bat activity was negative $(-0.396)$ in the statistical model. As this effect is calculated only after the variance explained by the $\mathrm{BHI}$ is removed, we understand this result as an indication that the BHI overestimates the overall effect of the highway. This means that the flight friction assigned to highways in the primary map should be adjusted accordingly.

Due to its mechanistic nature, PREBAT is always transparent in terms of the variables included in the weighting of sites. Independent of the purpose of a bat inventory, its indices allow impartial choices of sampling locations based on clearly defined criteria. The input data for PREBAT is publicly available, and the steps for the construction of the indices are

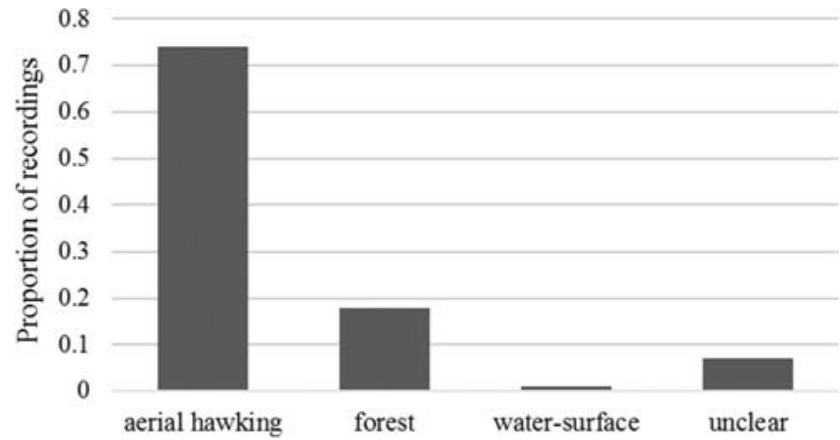

Fig. 6 Recording frequencies of different ecological guilds. Bars represent the proportion of recordings for each guild compared with the total number of recordings $(n=16,030)$. Recordings of Myotis sp. or Microchiroptera were ambiguous and could therefore not be assigned to any of the guilds 
Table 3 Comparison of $\triangle \mathrm{AICc}$ values of statistical models. The first column shows which variables were included in each model and whether they were tested separately, in addition $(+)$ or in interaction $\left(^{*}\right)$. The variables were bat habitat index $(\mathrm{BHI})$, flight friction $(\mathrm{FF})$, insect abundance (IA), colony movement (CM), and distance to the highway E18 (dist). The subscript stands for the area over which the respective values were averaged, 30, 200, and $500(\mathrm{~m})$ refer to the radius of a circle surrounding each site. All models in the first three columns were based on a sample of 50 observations (i.e. one observation per site). Models in the last five columns were based on a sample of 200 observations (i.e. 4 observations per site). The best models are indicated in italic; the values in bold indicate $\triangle \mathrm{AICc}$ values smaller than 2 . Models where $\triangle \mathrm{AICc}$ values were larger than 2 for all response variables are not shown

\begin{tabular}{|c|c|c|c|c|c|c|c|c|}
\hline \multirow[b]{2}{*}{$\begin{array}{l}\text { Explanatory } \\
\text { variables }\end{array}$} & \multicolumn{3}{|l|}{$n=50$} & \multicolumn{5}{|l|}{$n=200$} \\
\hline & $\begin{array}{l}\text { Total number } \\
\text { of species }\end{array}$ & $\begin{array}{l}\text { Number of } \\
\text { regular species }\end{array}$ & $\begin{array}{l}\text { Number of very } \\
\text { regular species }\end{array}$ & $\begin{array}{l}\text { Number of } \\
\text { species }\end{array}$ & $\begin{array}{l}\text { Total } \\
\text { activity }\end{array}$ & $\begin{array}{l}\text { Activity } \\
\text { forest } \\
\text { species }\end{array}$ & $\begin{array}{l}\text { Activity aerial- } \\
\text { hawking species }\end{array}$ & $\begin{array}{l}\text { Activity water- } \\
\text { surface species }\end{array}$ \\
\hline $\mathrm{BHI}_{30}$ & 0.73 & 5.16 & 9.90 & 4.61 & 5.23 & 6.38 & 5.26 & 6.11 \\
\hline $\mathrm{BHI}_{200}$ & 1.00 & 4.99 & 9.00 & 5.64 & 3.16 & 1.49 & 4.68 & 4.23 \\
\hline $\mathrm{BHI}_{500}$ & 1.68 & 6.00 & 10.87 & 8.23 & 5.70 & 5.63 & 5.75 & 6.14 \\
\hline $\mathrm{FF}_{30}$ & 0.69 & 6.54 & 12.32 & 6.03 & 6.78 & 8.31 & 5.65 & 0.00 \\
\hline $\mathrm{FF}_{200}$ & 1.62 & 8.74 & 16.52 & 9.97 & 6.50 & 10.53 & 5.07 & 7.41 \\
\hline $\mathrm{FF}_{500}$ & 1.09 & 8.89 & 16.19 & 9.90 & 6.03 & 10.71 & 4.49 & 8.02 \\
\hline $\mathrm{IA}_{30}$ & 1.59 & 8.43 & 15.49 & 8.82 & 6.77 & 9.99 & 5.62 & 7.54 \\
\hline $\mathrm{IA}_{200}$ & 1.46 & 7.48 & 13.20 & 8.32 & 5.77 & 4.55 & 5.83 & 5.74 \\
\hline $\mathrm{IA}_{500}$ & 1.71 & 7.81 & 13.11 & 9.32 & 6.68 & 7.58 & 5.64 & 7.00 \\
\hline $\mathrm{CM}_{30}$ & 0.00 & 0.00 & 0.00 & 0.00 & 0.21 & 4.90 & 0.00 & 4.28 \\
\hline $\mathrm{CM}_{200}$ & 0.81 & 3.40 & 8.70 & 4.78 & 0.78 & 5.11 & 0.91 & 5.28 \\
\hline $\mathrm{CM}_{500}$ & 1.67 & 4.93 & 12.02 & 7.82 & 3.50 & 7.54 & 3.67 & 6.17 \\
\hline $\mathrm{BHI}_{30}+$ dist & 1.35 & 7.37 & 11.53 & 4.94 & 3.63 & 8.09 & 4.90 & 7.85 \\
\hline $\mathrm{BHI}_{200}+$ dist & 1.62 & 7.19 & 10.62 & 6.06 & 1.02 & 2.98 & 4.14 & 5.89 \\
\hline $\begin{array}{c}\mathrm{BHI}_{200}+\text { dist }+ \\
\mathrm{BHI}_{200} * \text { dist }\end{array}$ & 3.27 & 9.46 & 12.42 & 7.99 & 0.00 & 0.00 & 5.06 & 5.01 \\
\hline
\end{tabular}

described in detail above. Spreading PREBAT amongst consulting agencies and other potential users would lead to a standardization of sampling strategies and therefore increased comparability of results, because commonly occurring
Table 4 Effect sizes and significance levels of the best-performing models. Only those models with $\triangle$ AICc values of 0 were investigated for effect sizes and significance of effects. The total number of species, number of regular species, and the number of very regular species were tested using the dataset with 50 samples (one per site); the other response variables were tested using the dataset with 200 samples (one per autobox, i.e. four per site). The italicized data indicate the variables, their effect sizes (i.e. estimate), and the $p$ values for their effects. Random effects factors and covariates are not shown

\begin{tabular}{|c|c|c|c|c|c|c|c|c|}
\hline Response variable & Residual deviance & Df & Explanatory variables & Estimate & SE & $Z$ value & $p$ value & \\
\hline Total number of species & 27.4 & 48 & $C M_{30}$ & -0.0003 & 0.0002 & -1.287 & 0.198 & $n s$ \\
\hline Number of regular species & 43.9 & 48 & $C M_{30}$ & -0.0012 & 0.0004 & -2.829 & 0.00467 & $* *$ \\
\hline Number of very regular species & 48.6 & 48 & $C M_{30}$ & -0.0022 & 0.0006 & -3.555 & 0.000378 & $* * *$ \\
\hline Number of species & 769.2 & 195 & $C M_{30}$ & -0.1737 & 0.0534 & -3.252 & 0.001148 & $* *$ \\
\hline \multirow[t]{3}{*}{ Total activity } & \multirow[t]{3}{*}{5063.3} & \multirow[t]{3}{*}{191} & $\mathrm{BHI}_{200}$ & 0.3443 & 0.1795 & 1.918 & 0.0551 & . \\
\hline & & & dist & -0.3958 & 0.0176 & -2.244 & 0.0248 & $*$ \\
\hline & & & $\mathrm{BHI}_{200} *$ dist & -0.3760 & 0.2071 & -1.816 & 0.0694 & . \\
\hline \multirow[t]{3}{*}{ Activity forest species } & \multirow[t]{3}{*}{2048.7} & \multirow[t]{3}{*}{192} & $\mathrm{BHI}_{200}$ & 0.5649 & 0.1799 & 3.139 & 0.00169 & $* *$ \\
\hline & & & dist & -0.1588 & 0.1761 & -0.902 & 0.36693 & \\
\hline & & & $\mathrm{BHI}_{200} *$ dist & -0.4846 & 0.2072 & -2.339 & 0.01934 & $*$ \\
\hline Activity aerial-hawking species & 3982.7 & 193 & $C M_{30}$ & -0.5826 & 0.2343 & -2.487 & 0.0129 & $*$ \\
\hline Activity water-surface species & 466.5 & 195 & $F F_{30}$ & -0.6877 & 0.2545 & -2.702 & 0.0069 & $* *$ \\
\hline
\end{tabular}


subject-dependent differences in inventory results (Wallin 1949, Faanes \& Bystrak 1981, Fitzpatrick et al. 2009) would be avoided.

The first main advantage of PREBAT is that it splits the prediction of bat occurrence into two separate processes underlying this occurrence, i.e. food availability and flight friction. This distinguishes it from other habitat models, for example species distribution models (e.g. Razgour et al. 2011, De La Cruz \& Ward 2016). Differentiating between habitat use for foraging and habitat use for transporting allows estimation of the importance of a given site for individuals, populations, or species. The second main advantage is that by including flight friction, PREBAT gains a measure of connectivity. In PREBAT, the connectivity can be looked at both at a large scale, e.g. to assess the overall connectivity between populations, and at a small scale, e.g. to identify essential movement corridors through an otherwise impenetrable landscape. With growing fragmentation of the landscape, ensuring connectivity at all spatial scales is becoming increasingly important for the persistence of populations and species (Dool et al. 2016, Rocha et al. 2017).

Especially in the planning of large infrastructure projects, e.g. construction of new highways or railway roads, connectivity is an important factor when assessing potential environmental impacts because the planned structure crosses the area and therefore might significantly reduce the connectivity for some species (Trafikverket 2015). PREBAT could be used as an indicator in preliminary assessments of conflict potential of infrastructure or exploitation projects. In the creation of the indices, habitat preferences of forest-living bat species were intentionally weighted more strongly than the preferences of other groups, because conflicts occur most frequently with those species (Trafikverket 2016). Consequently, the indices are most suitable for inventories and conflict assessments of forest species. When using PREBAT to identify potential areas of conflict, however, it is important to keep in mind its restrictions. It identifies key foraging habitats during spring but not the location of hibernating sites. A location with low index values can therefore not directly be interpreted as never being utilized by bats.

When comparing values of PREBAT indices to inventory data, it is also important to remember that PREBAT does not per se predict bat occurrence, but rather potential occurrence. Factors like variation between years, random events, or territorial behaviours, which might affect observation data, are not taken into consideration. Furthermore, differences in detection probability due to variation in vegetation density or because of species-specific differences in volume and frequency of the calls are not modelled in any index. For future use of PREBAT, we highly recommend including a parameter for habitat structure or vegetation density into the analysis to correct for this factor.
PREBAT values should be interpreted only within the same region, because the maximum number of species might differ at larger scales. In Sweden, for example, there is a strong latitudinal gradient with 19 bat species in the south and only one in the north (Ahlén 2011).

\section{Outlook}

The performance of the PREBAT indices strongly depends on the accuracy of the environmental input data used to construct the primary maps of insect abundance, flight friction, and available colony sites as well as the model parameters used to construct those. The values for insect abundance and flight friction are, for the moment, set manually according to the best available information and expert estimation. Optimizing the individual values of these maps has a great potential to improve the overall performance of the indices. Three possible ways might lead to that goal: an empiric study of the primary factors themselves (insect abundance, flight friction for bats, suitability of potential colony sites) in all different categories, a computational test of all possible value combinations where the resulting index is compared with an empiric dataset of bat occurrences, or the use of an optimizing algorithm that would lead to those value combinations that perform best, again compared with an empiric dataset.

\section{Conclusion}

The indices produced by the connectivity-based habitat model PREBAT are significantly correlated with bat occurrence. The indices performed particularly well when predicting the number of regular species as well as the activity of forest bats. It did not perform well when predicting overall bat activity or the total number of species.

The results from this study indicate where the procedures of the PREBAT indices have to be adjusted and where further improvements are needed.

Acknowledgements We are grateful to Claus Rüffler, Charles Campbell, Göran Arnqvist, and Malin Aronsson for support and advice for the project design and the data analysis; to Simon Kärvemo for help with the geographical data; to Lara Millon and Meagon Tunón for assistance in the field; to Alexander Eriksson, Lara Millon, Björn Palmqvist, and Martin Brüsin from the agency Ecocom AB for analysis of the acoustic data; and to Hanna Modin, Eduardo Ottimofiore, and Andreas Seiler for feedback on earlier versions of the manuscript.

Funding information Open access funding provided by Swedish University of Agricultural Sciences. This study was supported by the Swedish Transport Administration, contract number TRV3714. 


\section{Compliance with ethical standards}

Conflict of interest The authors declare that they have no conflict of interest.

Open Access This article is licensed under a Creative Commons Attribution 4.0 International License, which permits use, sharing, adaptation, distribution and reproduction in any medium or format, as long as you give appropriate credit to the original author(s) and the source, provide a link to the Creative Commons licence, and indicate if changes were made. The images or other third party material in this article are included in the article's Creative Commons licence, unless indicated otherwise in a credit line to the material. If material is not included in the article's Creative Commons licence and your intended use is not permitted by statutory regulation or exceeds the permitted use, you will need to obtain permission directly from the copyright holder. To view a copy of this licence, visit http://creativecommons.org/licenses/by/4.0/.

\section{References}

Ahlén I (2011) Fladdermusfaunan i Sverige. Arternas utbredning och status. Kunskapsläget 2011. Fauna och Flora 106:2-19

Akaike H. 1998. Information theory and an extension of the maximum likelihood principle. Selected papers of Hirotugu Akaike

Artdatabanken (2015) Rödlistade arter i Sverige. Artdatabanken SLU, Uppsala

Ashrafi S, Rutishauser M, Ecker K, Obrist MK, Arlettaz R, Bontadina F (2013) Habitat selection of three cryptic Plecotus bat species in the European Alps reveals contrasting implications for conservation. Biodivers Conserv 22:2751-2766

Bates D, Mächler M, Bolker B, Walker S (2015) Fitting linear mixedeffects models using lme4. J Stat Softw. https://doi.org/10.18637/jss. v067.i01

Bennett VJ, Zurcher AA (2013) When corridors collide: road-related disturbance in commuting bats. J Wildl Manag 77:93-101

Berthinussen A, Altringham J (2012) The effect of a major road on bat activity and diversity. J Appl Ecol 49:82-89

Burnham KP, Anderson DR (2002) Model selection and multimodel inference: a practical information-theoretic approach, 2nd edn. Springer, New York

Ciechanowski M (2002) Community structure and activity of bats (Chiroptera) over different water bodies. Mamm Biol 67:276-285

Council Directive 92/43/EEC

de Jong J. 1994. Distribution patterns and habitat use by bats in relation to landscape heterogeneity, and consequences for conservation. Report, Swedish University of Agricultural Sciences

de Jong J, Ahlén I (1991) Factors affecting the distribution pattern of bats in Uppland, central Sweden. Holarct Ecol 14:92-96

De La Cruz JL, Ward RL (2016) Summer-habitat suitability modeling of Myotis sodalis (Indiana bat) in the eastern mountains of West Virginia. Northeast Nat 23:100-117

De Montis A, Martín B, Ortega E, Ledda A, Serra V (2017) Landscape fragmentation in Mediterranean Europe: a comparative approach. Land Use Policy 64:83-94

Dool SE, Puechmaille SJ, Kelleher C, McAney K, Teeling EC (2016) The effects of human-mediated habitat fragmentation on a sedentary woodland-associated species (Rhinolophus hipposideros) at its range margin. Acta Chiropter 18:377-393

Ducci L, Agnelli P, Di Febbraro M, Frate L, Russo D, Loy A, Carranza ML, Santini G, Roscioni F (2015) Different bat guilds perceive their habitat in different ways: a multiscale landscape approach for variable selection in species distribution modelling. Landsc Ecol $30: 2147-2159$

Ecocom AB (2017) Omnibat. Ecocom, Kalmar

Ellis EC, Klein Goldewijk K, Siebert S, Lightman D, Ramankutty N. 2010. Anthropogenic transformation of the biomes, 1700 to 2000: anthropogenic transformation of the biomes. Global Ecology and Biogeography no-no.

Ellis EC, Ramankutty N (2008) Putting people in the map: anthropogenic biomes of the world. Front Ecol Environ 6:439-447

ESRI. 2016. ArcMap

Evans KL, Wilson JD, Bradbury RB (2007) Effects of crop type and aerial invertebrate abundance on foraging barn swallows Hirundo rustica. Agric Ecosyst Environ 122:267-273

Faanes CA, Bystrak D. 1981. The role of observer bias in the North American Breeding Bird Survey. Estimating numbers of terrestrial birds, pp. 353-359. Cooper Ornithological Society, Lawrence, Kansas

Fahrig L, Rytwinski T (2009) Effects of roads on animal abundance: an empirical review and synthesis. Ecol Soc. https://doi.org/10.5751/ ES-02815-140121

Fitzpatrick MC, Preisser EL, Ellison AM, Elkinton JS (2009) Observer bias and the detection of low-density populations. Ecol Appl 19: 1673-1679

Fukui D, Murakami M, Shigeru N, Toshiki A (2006) Effect of emergent aquatic insects on bat foraging in a riparian forest. J Anim Ecol 75: $1252-1258$

Gaisler J, Řehák Z, Bartonička T (2009) Bat casualties by road traffic (Brno-Vienna). Acta Theriol 54:147-155

Gkritza K, Baird M, Hans ZN (2010) Deer-vehicle collisions, deer density, and land use in Iowa's urban deer herd management zones. Accid Anal Prev 42:1916-1925

Hagen EM, Sabo JL (2012) Influence of river drying and insect availability on bat activity along the San Pedro River, Arizona (USA). J Arid Environ 84:1-8

Hansen MC, Potapov PV, Moore R, Hancher M, Turubanova SA, Tyukavina A, Thau D, Stehman SV, Goetz SJ, Loveland TR, Kommareddy A, Egorov A, Chini L, Justice CO, Townshend JRG (2013) High-resolution global maps of 21st-century forest cover change. Science 342:850-853

Hunt LM, Lester N (2009) The effect of forestry roads on access to remote fishing lakes in northern Ontario, Canada. N Am J Fish Manag 29:586-597

Jackson JK, Resh VH (1989) Distribution and abundance of adult aquatic insects in the forest adjacent to a North California stream. Environ Entomol 18:278-283

Kelm DH, Lenski J, Kelm V, Toelch U, Dziock F (2014) Seasonal bat activity in relation to distance to hedgerows in an agricultural landscape in central Europe and implications for wind energy development. Acta Chiropter 16:65-73

Kerth G, Melber M (2009) Species-specific barrier effects of a motorway on the habitat use of two threatened forest-living bat species. Biol Conserv 142:270-279

Kitzes J, Merenlender A (2014) Large roads reduce bat activity across multiple species. PLoS One. https://doi.org/10.1371/journal.pone. 0096341

Kniowski AB, Gehrt SD (2014) Home range and habitat selection of the Indiana bat in an agricultural landscape: home range and habitat use by Indiana bats. J Wildl Manag 78:503-512

Lazure L, Fenton MB (2011) High duty cycle echolocation and prey detection by bats. J Exp Biol 214:1131-1137

Lesiński G, Sikora A, Olszewski A (2011) Bat casualties on a road crossing a mosaic landscape. Eur J Wildl Res 57:217-223

Luo J, Siemers BM, Koselj K (2015) How anthropogenic noise affects foraging. Glob Chang Biol 21:3278-3289

Metria AB. 2015. CadasterENV 
Nelson JJ, Gillam EH (2017) Selection of foraging habitat by female little brown bats (Myotis lucifugus). J Mammal 98:222-231

Niemi M, Rolandsen CM, Neumann W, Kukko T, Tiilikainen R, Pusenius J, Solberg EJ, Ericsson G (2017) Temporal patterns of moosevehicle collisions with and without personal injuries. Accid Anal Prev 98:167-173

Pettersson Elektronik AB. BatSound. Pettersson Electronics and Acoustics AB

R Core Team (2017) R: a language and environment for statistical computing. R Foundation for Statistical Computing, Vienna

Razgour O, Hanmer J, Jones G (2011) Using multi-scale modelling to predict habitat suitability for species of conservation concern: the grey long-eared bat as a case study. Biol Conserv 144:2922-2930

Rocha R, López-Baucells A, Farneda FZ, Groenenberg M, Bobrowiec PED, Cabeza M, Palmeirim JM, Meyer CFJ (2017) Consequences of a large-scale fragmentation experiment for Neotropical bats: disentangling the relative importance of local and landscape-scale effects. Landsc Ecol 32:31-45

Russell A, Butchkoski C, Saidak L, McCracken G (2009) Road-killed bats, highway design, and the commuting ecology of bats. Endanger Species Res 8:49-60

Schaub A, Ostwald J, Siemers BM (2008) Foraging bats avoid noise. J Exp Biol 211:3174-3180

Seibold S, Buchner J, Bässler C, Müller J (2013) Ponds in acidic mountains are more important for bats in providing drinking water than insect prey: oligotrophic ponds - a source of water for bats. J Zool 290:302-308

Seiler A (2004) Trends and spatial patterns in ungulate-vehicle collisions in Sweden. Wildl Biol 10:301-313
Siemers BM, Schaub A (2011) Hunting at the highway: traffic noise reduces foraging efficiency in acoustic predators. Proc Roy Soc 278:1646-1652

SMHI (2018) SMHI Öppna data. online: http://opendata-catalog.smhi.se/ explore/. Accessed March 8, 2018

Trafikverket (2015) Transportinfrastrukturens påverkan på biologisk mångfald - en konceptuell modell för kommunikation och planering. Trafikverket, Borlänge

Trafikverket (2016) Anpassning av transportinfrastrukturen som ett bidrag till en fungerande grön infrasktruktur. In: Planera, bygga och sköta. Borlänge, Trafikverket

van der Ree R, Smith DJ, Grilo C (2015) The ecological effects of linear infrastructure and traffic: challenges and opportunities of rapid global growth. In: van der Ree R, Smith DJ, Grilo C (eds) Handbook of road ecology. John Wiley \& Sons Ltd, Chichester, pp 1-9

Verboom B, Huitema H (1997) The importance of linear landscape elements for the pipistrelle Pipistrellus pipistrellus and the serotine bat Eptesicus serotinus. Landsc Ecol 12:117-125

Wallin P (1949) Volunteer subjects as a source of sampling bias. Am J Sociol 54:539-544

Wordley CFR, Sankaran M, Mudappa D, Altringham JD (2015) Landscape scale habitat suitability modelling of bats in the Western Ghats of India: bats like something in their tea. Biol Conserv 191:529-536

Zurcher AA, Sparks DW, Bennett VJ (2010) Why the bat did not cross the road? Acta Chiropter 12:337-340

Publisher's note Springer Nature remains neutral with regard to jurisdictional claims in published maps and institutional affiliations. 